\title{
EFFECTS OF GRAZING EXCLUSION BY FENCE ON VEGETATION CHARACTERISTICS AND COMMUNITY DIVERSITY OF MONGOLIAN GRASSLANDS
}

\author{
GUO, T. ${ }^{1 *}-$ LIAO, H. R. ${ }^{1}-$ TUVSHINTOGTOKH, I. ${ }^{2}$ \\ ${ }^{l}$ Department of Ecology, College of Urban and Environmental Sciences, Peking University, \\ Beijing, China \\ ${ }^{2}$ Department of Vegetation Ecology and Plant Resource, Institute of General and Experimental \\ Biology, Mongolian Academy of Sciences, Ulaanbaatar, Mongolia \\ *Corresponding author \\ e-mail: tongg@pku.edu.cn \\ (Received $11^{\text {th }}$ Jun 2020; accepted $20^{\text {th }}$ Aug 2020)
}

\begin{abstract}
Grazing exclusion by fence was often used in the management of grassland ecosystems. However, the direction and the strength of effects of grazing exclusion on grassland vegetation characteristics and community diversity are currently disputable. In addition, little research was conducted on the effects of grazing exclusion on vegetation phenology. In this study, we aim to determine the effects of grazing exclusion on vegetation characteristics, community diversity and vegetation phenological periods. For this, we performed a fencing experiment in three grassland types in Mongolia. Each grassland type was set by two treatments: grazing exclusion and freely grazing. We found that grazing exclusion generally increased vegetation height regardless of grassland type. In contrast, variations of vegetation cover caused by grazing exclusion were not consistent in three grassland types. Grazing exclusion decreased species richness and Shannon diversity. However, community evenness varied little without grazing disturbances. Grazing exclusion advanced the vegetation phenological periods in three grassland types. This study fills the knowledge gap of the effects of grazing exclusion on vegetation characteristics, community diversity and vegetation phenological development in Mongolian grasslands. Other management strategies like rotational grazing and reseeding are encouraged to be used in tandem with grazing exclusion to restore Mongolian rangelands.
\end{abstract}

Keywords: vegetation cover, species richness, Shannon-Wiener diversity, phenological periods, grassland type

\section{Introduction}

Grasslands are an important component of terrestrial ecosystems and greatly influence provisions of ecosystem services like food supplies, biodiversity maintenance and climate regulation (Solen et al., 2019). Grasslands sustain nomadic peoples and facilitate the production of livestock (Kemp et al., 2013). However, increasing anthropogenic activities, in particular livestock volume and the resulting overgrazing often cause grassland degradation, especially in arid and semi-arid regions (Ahlborn et al., 2020; Bosch, 1989). Overgrazing significantly alters the community structure through decreasing vegetation cover and species diversity (Mysterud, 2006). Simultaneously, overgrazing has important management implications, since it leads to great losses of economic resources and threatens plant diversity (Stein et al., 2016).

To restore degraded grassland ecosystems, grazing exclusion by fence is a useful management practice (Xiong et al., 2016). Fencing can be regarded as a direct reference to determine the benefits of grazing removal on ecosystem services and functioning in grasslands (Davies and Boyd, 2019). Nevertheless, grazing gradient experiments focus 
on ecological consequences of livestock grazing intensity (Stein et al., 2016). Degraded grasslands enter self-recovery state in case grazing activities are forbidden for a suitable period (Golodets et al., 2010). A large number of researches have been conducted to examine effects of grazing exclusion on vegetation characteristics and diversity under different grazing regimes (Augustine et al., 2017; Koch et al., 2017; Sagar et al., 2019; Yao et al., 2019). Grazing exclusion by fence often increases vegetation height and cover (Li et al., 2014; Zhu et al., 2016a). However, the findings are not consistent in terms of plant diversity. Palatable plant species may benefit from fencing owing to their fast tissue regrowth (Guo et al., 2016). Grazing exclusion may decrease richness of grazing avoided species since slow growing tissue constrains their competition capacity (Rota et al., 2016). In addition, the response of community diversity to grazing exclusion is largely determined by fencing time. Grazing history strongly affects the forage quality of grasses (Adler et al., 2004). Long-term grazing exclusion by fence generally has negative effects on the community diversity owing to density effects (Wu et al., 2009; Yao et al., 2019). Short-term grazing exclusion is beneficial for the community vegetation diversification since most of plant species rapidly grow without grazing (Zhang and Zhao, 2015). Oppositely, grassland species richness and diversity were also found to increase under the condition of long-term grazing exclusion (Sagar et al., 2019; Zhu et al., 2016a). Several studies show that grazing exclusion by fence plays little role in maintaining grassland plant diversity (Koch et al., 2017; Xiong et al., 2016). These fencing experiments were implemented in different grassland types characterized by specific combinations of plant species. Diverse responses of plant species to grazing exclusion largely shape the structure and the diversity of grassland communities. However, it needs to be strengthened for effects of grassland type and their interaction with grazing removal time on characteristics and the diversity of vegetation communities. Nevertheless, several long-term grazing exclusion experiments have been carried out to explore these effects (Goheen et al., 2018; Irisarri et al., 2016).

Besides vegetation characteristics and community diversity, grazing exclusion also strongly affects vegetation phenological development. Key aspects of vegetation phenology such as green up, seeding and flowering have profound implications for restoration of degraded grasslands. Short-term grazing exclusion advances the phenology of Kobresia pygmaea (Zhu et al., 2016b). Moreover, grazing alters the flowering probability of the short-lived perennial Cirsium vulgare (Marco and Silvertown, 2014). Annual grass species in the ungrazed plots flower earlier than in the grazed ones (Bergmeier, 1998). However, different species have distinctive sensitivities and subsequent phenological response to grazing exclusion. In addition, the consequences of grazing for the same species are likely to vary across different grassland types, which are characterized by site-specific grazing history and vegetation community properties (Stahlheber and D'Antonio, 2013). Therefore, currently available work needs to be strengthened towards clarifying the effects of grazing exclusion on the vegetation phenology.

To fill the above-mentioned knowledge gap, the study was conducted in three grassland types of Mongolia, namely meadow, mountain steppe and dry steppe. Grasslands occupy $83.4 \%$ of the land area in Mongolia, while the nomadic people are the majority among population ( $\mathrm{Li}$ et al., 2005). Livestock grazing is a traditional land use form of the Mongolian grasslands (Ahlborn et al., 2020). With an increase of the population, most grasslands in Mongolia are experiencing overgrazing and an increased threat of degradation (Wang et al., 2020). Restoring the degraded grasslands is 
necessary for a long-term utilization of natural resources in the vast grassland region. Although a grazing restriction has been implemented for a period in this area, little is known about effects of grazing exclusion on vegetation characteristics, community diversity and vegetation phenology. We examined the response of these factors to grazing exclusion through performing a 6-10 years enclosure trial and addressed the following questions: (1) How does grazing exclusion by fence affect vegetation characteristics and community diversity in Mongolian grasslands? (2) Is the impact of grazing exclusion dependent on grassland type? (3) How does vegetation phenology respond to grazing exclusion?

\section{Materials and methods}

\section{Study site}

Three grassland types, namely dry steppe $\left(47^{\circ} 12^{\prime} \mathrm{N}, 108^{\circ} 44^{\prime} \mathrm{E}\right)$, mountain steppe $\left(48^{\circ} 17^{\prime} \mathrm{N}, 108^{\circ} 43^{\prime} \mathrm{E}\right)$ and meadow $\left(48^{\circ} 11^{\prime} \mathrm{N}, 108^{\circ} 26^{\prime} \mathrm{E}\right)$, are located in the southeast of the Ulaanbaatar on the Mongolian Plateau (Fig. 1). According to historical climatological data from 1993 to 2002 , mean annual temperature is $1.2{ }^{\circ} \mathrm{C}$, with the highest mean daily temperature in July $\left(21.4^{\circ} \mathrm{C}\right)$ and the lowest temperature in January $\left(-22.9^{\circ} \mathrm{C}\right)$. Mean annual precipitation is less than $200 \mathrm{~mm}$. More than $50 \%$ of annual precipitation occurs during the vegetation growing season (June to September). The soil of the area is mostly composed of burozem and of a high calcium content. The vegetation communities in three grassland types are characterized by various combinations of dominant species: Potentilla anserine, Carex duriuscula, Carex pediformis, Carex coriophora and Taraxacum cerataphorum in the meadow; Potentilla acaulis, Aster alpinus, Festuca lenensis, Carex pediformis and Stipa baicalensis in the mountain steppe; Artemisia frigida, Allium bidentatum, Artemisia adamsii, Kochia prostrata and Astragalus galacitites in the dry steppe. Most plant species in the area green up in late April and senesce in late October. The average grazing intensity is 7 large stock units per 100 ha in the meadow and the mountain steppe, while a heavier grazing intensity occurs in the dry steppe with a value of 11 large stock units per 100 ha. One large stock unit could be simply deemed as 1 cow.

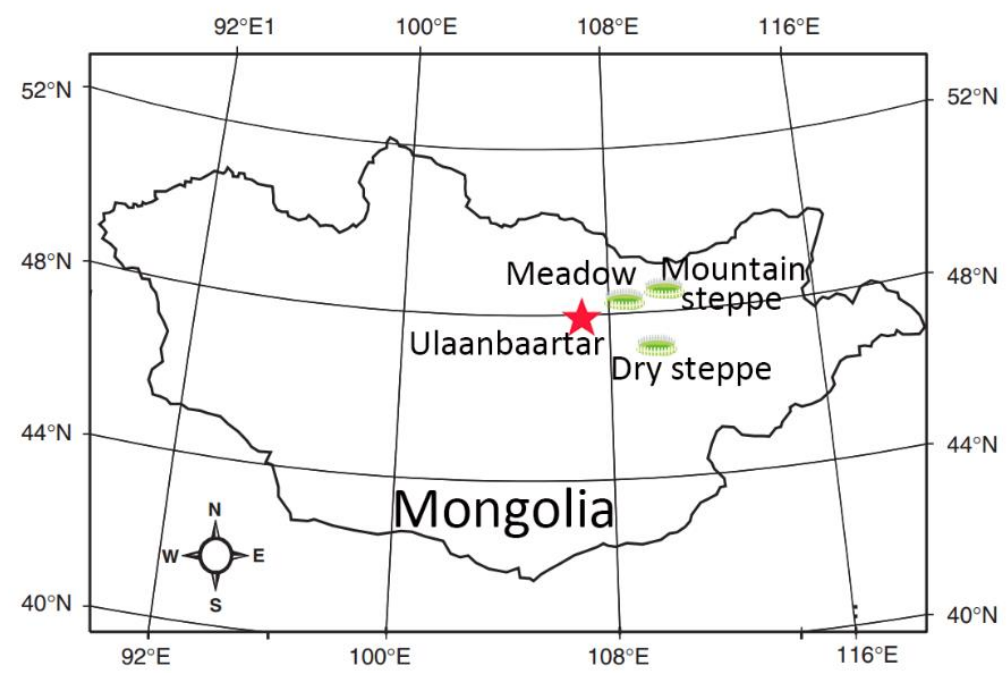

Figure 1. Geographical locations of three Mongolian grassland types 


\section{Experimental design}

To examine effects of grazing exclusion on vegetation characteristics, community diversity and vegetation phenology of the Mongolian grasslands, the enclosure was set up to completely exclude livestock grazing in the meadow from 2009, the mountain steppe and the dry steppe from 2013 (Fig. 2). We set one enclosure in each grassland type. Each enclosure covered an area of 0.1 ha $(50 \mathrm{~m} \times 20 \mathrm{~m})$. Three sites of the enclosure were selected over a homogeneous area and had similar geographical conditions like slope, elevation and soil types. A freely grazed area was selected as the control treatment nearby the enclosure of each typical grassland. That is, each grassland was carried out by two treatments: grazing exclusion by fence (GE) and freely grazing (FG). In 2013, we randomly sampled ten quadrats $(1 \mathrm{~m} \times 1 \mathrm{~m})$ of fenced plots in the mountain steppe and the dry steppe respectively. Similarly, we chose ten quadrats $(0.5 \mathrm{~m} \times 0.5 \mathrm{~m})$ of fenced plots in the meadow, where grasses were much denser. The quadrats in the fence had a distance of $5 \mathrm{~m}$ to fence margins to minimize edge effects. Simultaneously, ten quadrats were separately sampled in grazed plots for three grassland types. The quadrats in grazed plots had the same distance of $20 \mathrm{~m}$ to the corresponding ones in fenced plots. We used a bootstrapping method to sample 3 quadrats from 10 for both fenced and grazed plots in each grassland. We performed the implementation 10 times in three grassland types respectively. We found that a small number of quadrats depicted well general changes in vegetation cover regardless of treatments and grassland type (see Table Al in the Appendix). Thus, we separately determined three quadrats in the dry steppe, the mountain steppe and the meadow. Then we sampled the same quadrats in the following years. We used the same quadrats to weaken confounding effects of abiotic factors like soil properties on the vegetation communities. Effects of grazing exclusion on grassland communities were often studied from a taxonomic perspective. Thus, the number, the height, vegetation cover and phenology of plant species, as well as the number of species individual were investigated in each quadrat at the end of August (late in the growing season) of every year. We measured vegetation cover through visual estimates. Vegetation height was determined from the surface of ground to reproductive leaves or branches. The number of plant species was recorded according their vegetation cover in one quadrat. Specifically, we set a standard of the cover more than 0.05 to identify whether the species should be counted. We elaborately investigated 108 quadrats in a 6 consecutive years experiment ( 3 quadrats $\times 2$ treatments $\times 6$ years $\times 3$ grassland types). Moreover, we tried to examine the response of vegetation palatability to grazing exclusion. We classified all the plant species into two categories according to their palatability for livestock: palatable species (grass species and sedge species) and non-palatable species (forb species, Artemisia species and leguminous species) (Yao et al., 2019). We showed palatability-related results of the vegetation characteristics and the community diversity under treatments of grazing exclusion and freely grazing (see Table A2 in the Appendix). This aims to offer a mechanistic and supplementary interpretation of grazing exclusion effects on grassland communities.

We examined the response of vegetation to grazing exclusion in terms of phenology. Vegetation phenological periods were divided into five stages: germination, growth, bud, flower and seeds. The five periods were assigned with sequential numbers from 1 to 5 respectively. Categorization of the phenological stages followed the system of Moore et al. (1991). In case certain species had different values of phenological periods for one enclosure, the phenological period corresponding to the largest cover ratio 
(cover of one species divided by total cover of all species in one quadrat) among quadrats was determined as the phenology of the species. Then we evaluated the phenological period of the same species inside (ungrazed) and outside (grazed) the enclosure for three grassland types. To quantify effects of grazing exclusion on the vegetation phenological period, we established an evaluation index of relationship change of phenological stages $(E I R C P)$ to describe phenological differences between fenced plots and grazed plots. The index was calculated according to Equations 1 and 2.

$$
\begin{gathered}
A P S=\frac{\sum_{i=i}^{n} P S_{i}}{n} \\
E I R C P=\frac{A P S_{\text {inside }}-A P S_{\text {outside }}}{4}
\end{gathered}
$$

$P S_{i}$ denotes the phenological period of species $i$; APS denotes the average phenological period of all species inside (ungrazed) or outside (grazed) the enclosure; The number 4 represents the maximum phenological differences between inside and outside the enclosure. We assumed that it is impossible for the case that the phenological stage is 5 (seeds) in the fence plot, while the stage is 1 (germination) in the grazed plot. If EIRCP is larger than 0, then it means the vegetation phenology advances; If EIRCP is smaller than 0 , then it means the vegetation phenology delays. The value of ERCIP ranges from -1 to 1 .

We thereafter calculated the distribution of EIRCP relative to 0 in each grassland type. In addition, we provided species proportions in terms of phenological changes for three grassland types (see Fig. Al in the Appendix).

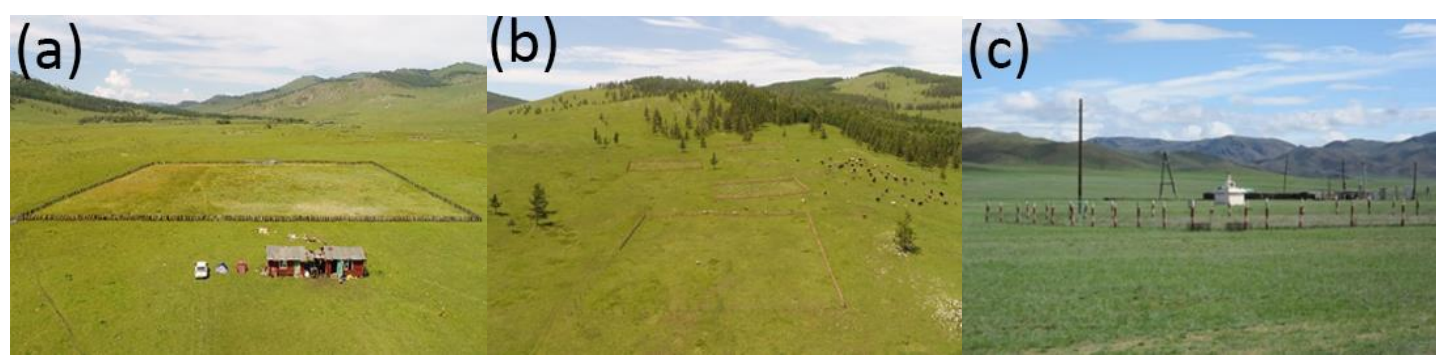

Figure 2. The picture of experimental sites: (a) meadow (b) mountain steppe (c) dry steppe

\section{Data analysis}

Vegetation characteristics of grassland communities were evaluated in terms of plant height and vegetation cover. Richness index (the number of plant species), ShannonWiener diversity index $\left(H^{\prime}\right)$ and Pielou evenness index $(E)$ were calculated for each quadrat.

$$
\begin{gathered}
\text { Richness }=S \\
H^{s}=-\sum_{i=1}^{S} P_{i}\left(\ln P_{i}\right) \\
E=\frac{H^{r}}{\ln S}
\end{gathered}
$$


$P_{i}$ denotes the cover ratio of species $i$ to total species; $H^{\prime}$ denotes Shannon-Wiener index; $E$ denotes Pielou evenness index.

We used Wilcoxon signed rank test to assess differences of the vegetation characteristics and the community diversity between grazing exclusion and grazed treatments within each year for three grassland types. Statistical analyses were performed using R software (R-core-Team, 2017).

\section{Results}

\section{Response of vegetation characteristics to grazing exclusion}

Grazing exclusion by fence significantly increased vegetation height for all three grassland types (Fig. 3). However, the height varied differently with grassland type. It was with a substantially higher height without grazing than the grazing scenario for the meadow, and a comparatively lower height than that of the other two grassland types under grazing treatment. Grazing exclusion generally did not facilitate the increment of vegetation cover. The response of vegetation cover to grazing also varied with grassland type. Grazing exclusion increased the cover in the dry steppe while decreased the cover in the meadow and the mountain steppe. In addition, the effect was only significant in the dry steppe. There was no clear inter-annual tendency of grazing exclusion induced variations of vegetation height and cover.
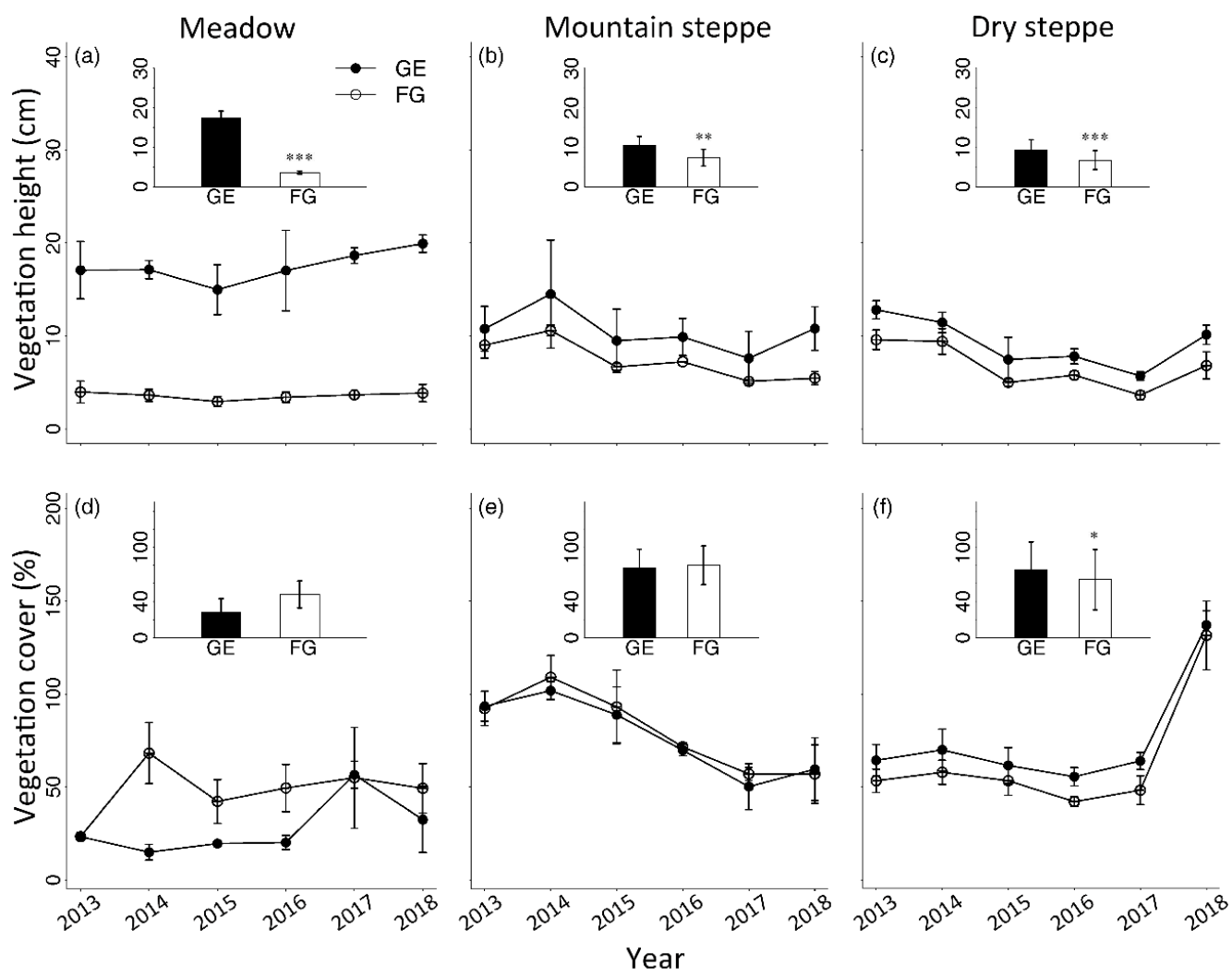

Figure 3. Vegetation height $(a, b, c)$ and cover $(d, e, f)$ under two treatments: grazing exclusion by fence $(G E)$ and freely grazing (FG) of three grassland types from 2013 to 2018. Scatter plots show time-series variations of vegetation characteristics. Bar plots attached show the average value of six years. Error bars are shown by standard deviation. Letters within bar plots indicate differences with a significant level $(P<0.05)$ between two treatments 


\section{Response of community diversity to grazing exclusion}

Grazing exclusion generally had negative effects on the species richness and the Shannon diversity in three grassland types (Fig. 4). Species richness in fenced plots significantly differed from that in grazed plots. Similarly, the effect of grazing exclusion suited well in terms of Shannon diversity in the meadow and the dry steppe, but performed weakly in the mountain steppe. No obvious differences of the community evenness were found between fenced plots and grazed plots. The inter-annual effects of grazing exclusion on the community diversity were lack of regularity for three grassland types.

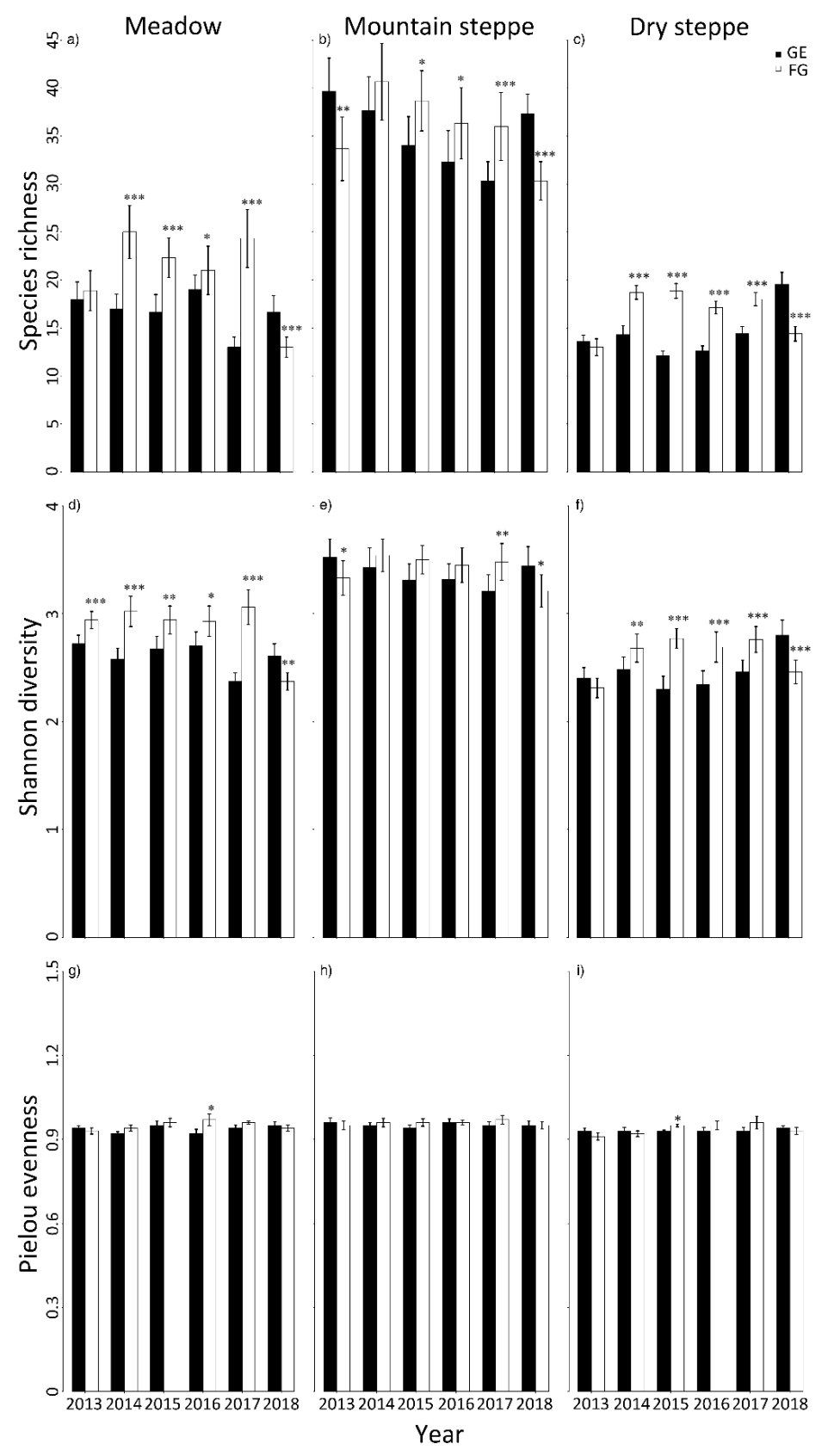

Figure 4. Species richness $(a, b, c)$, Shannon-Wiener diversity $(d, e, f)$ and Pielou evenness $(g$, $h, i)$ under treatments of grazing exclusion by fence $(G E)$ and freely grazing $(F G)$ in three grassland types from 2013 to 2018. Asterisks indicate a significance level of the statistical test $(* * *<0.001 ; * *<0.01 ; *<0.05)$ 


\section{Response of phenological characteristics to grazing exclusion}

Grazing exclusion by fence generally advanced vegetation phenological stages in three grassland types (Fig. 5). However, the phenology of the meadow and the mountain steppe vegetation postponed by 0.02 and 0.19 respectively in 2014. In addition, the positive phenological variations tended to be greater in the meadow than other two grasslands. Dry steppe vegetation often had earlier phenological stages than that of mountain steppe.

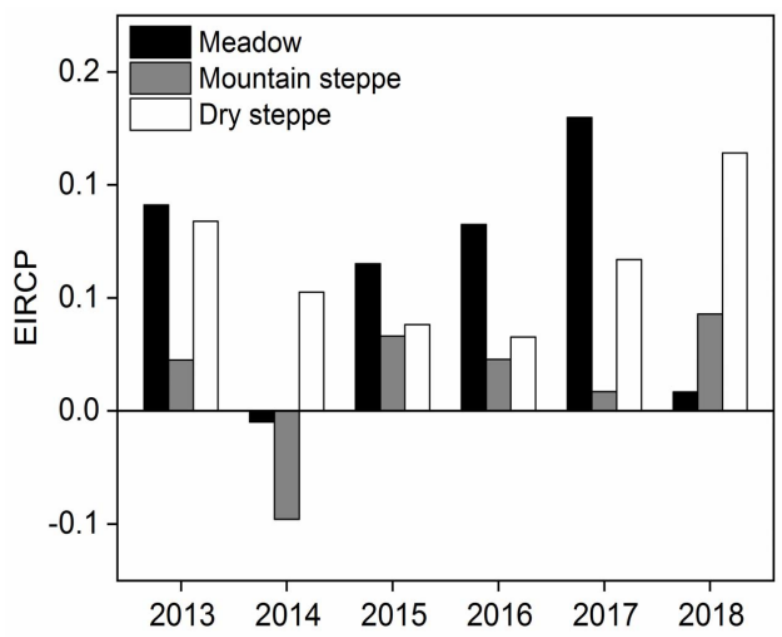

Figure 5. Vegetation phenological changes (fenced plots vs. grazed plots) in three grassland types from 2013 to 2018

\section{Discussion}

Livestock grazing is an important and direct way influencing grassland communities (Stein et al., 2016; Weiss and Jeltsch, 2015). Fencing is often considered as a useful tool to explore grazing exclusion effects on vegetation communities (Zhu et al., 2016b). Understanding the direction, the magnitude and mechanisms of grazing exclusion effects on vegetation communities greatly improves grassland management practices (Wang et al., 2014). In this study we focused on the response of aboveground vegetation indices to grazing exclusion by fence. Even though belowground parameters like soil properties and nutrients are also sensitive to grazing exclusion in Mongolian grasslands (Wang et al., 2019). Vegetation characteristics and diversity have been widely used to assess effects of grazing exclusion on grassland communities. However, the assessment is missing in Mongolian grasslands. Our study showed that grazing exclusion increased vegetation height and advanced vegetation phenological stages, but decreased community diversity. The effect of grazing exclusion varied with grassland type.

\section{Vegetation characteristics response to grazing exclusion in three grassland types}

Grazing exclusion by fence generally facilitated an increment of vegetation height for three Mongolian grasslands. This finding is in line with other fencing experiments in grasslands (Deng et al., 2014; Li et al., 2014), since tall plants are sensitive to livestock grazing (Díaz et al., 2007). In addition, positive changes in vegetation height induced by grazing exclusion did not exhibit a clear regularity of inter-annual variability. Grazing exclusion did not increase vegetation cover in the meadow and the mountain steppe, and 
significantly increased the cover in the dry steppe. The finding verifies different responses of vegetation cover to grazing exclusion across various steppes in Mongolian rangelands (Khishigbayar et al., 2015). Vegetation cover was more vulnerable to harsher environments. Fencing might stimulate a greater increment of the cover in the dry steppe. In addition, the meadow had a longer time since enclosure. This might explain a larger difference of vegetation cover between fenced and grazed plots. Recovery of vegetation cover is a lasting procedure. Li (2014) found vegetation needed 6 years to recover after grazing exclusion by fence in a degraded grassland in northeast China. For some savanna ecosystems these shifts can take many years (Goheen et al., 2018). Other management strategies like reseeding and fertilization may be performed to increase survival rates of plant species, thereby leading to an enhancement of vegetation cover. Moreover, variations of vegetation cover may be largely constrained by local climatic conditions. General arid environments in Mongolia hinder the restoration of vegetation cover. We further found that grazing exclusion positively affected vegetation cover of palatable species in the meadow and the mountain steppe, while the effect was not available in the dry steppe (see Table A2 in the Appendix). This indicates that analyses from a perspective of functional groups aid us to comprehensively understand effects of grazing exclusion on vegetation characteristics. The communities were further found to be generally composed of unpalatable species across years in three grassland types (see Table A2 in the Appendix). Palatable species are preferably selected by livestock (Guo et al., 2016). The result suggests that overgrazing in historical periods led to a decreased quality of forage grass and the dominance of unpalatable species in Mongolian grasslands. Thus, palatable species grow rapidly. Grazing history can impact the response of rangeland community cover and diversity to grazing management (Vermeire et al., 2018).

\section{Community diversity response to grazing exclusion in three grassland types}

We found that grazing exclusion had negative effects on the species richness and Shannon-Wiener diversity in three Mongolian grasslands. This is consistent with the findings in other grassland ecosystems (Wu et al., 2009; Yao et al., 2019; Zou et al., 2016). However, other studies showed contradictory results compared with ours (Sagar et al., 2019; Zhang and Zhao, 2015; Zhu et al., 2016a). Grazing leads to an occurrence of empty space, which allows more species to live on it. Grazing may also create the heterogeneity of habitats and thus benefits species coexistence (Guo et al., 2018). Another possible reason for the lower diversity in fenced plots is that grazing exclusion prevents seeds in freely grazed areas into the small fenced area (only 0.1 ha). Pielou evenness was found to be little controlled by grazing exclusion. Several studies have indicated that short-term grazing exclusion may be essential and important for improving species diversity (Jing et al., 2014; Xiong et al., 2016). Long-term fenced plots are likely to form climax species. This intensifies species competition for light and water resource, and thus decreases plant diversity (Zhu et al., 2016a). However, our results showed that the community diversity decreased in fenced plots regardless of years. This is not in line with typical discussions of fencing time impact on the community diversity. From a perspective of grassland management, grazing exclusion by fence is not an effective approach for restoring the diversity of the whole community in the degraded Mongolian grasslands. Moderate or rotational grazing rather than grazing exclusion by fence may be a better choice, since grazing weakens the dominance of certain undesirable species, allows the persistence of grazing-adapted 
species and thus promote species coexistence (Stahlheber and D'Antonio, 2013). Fencing treatment could be regarded as a scenario without disturbances, while freely grazing scenario was full of disturbances. Both scenarios may correspond to a lower species diversity level based on intermediate disturbance hypothesis (Connell, 1979). We found that grazing exclusion had positive effects on the richness of palatable species in the meadow and the mountain steppe, while the effect did not exist in the dry steppe (see Table A2 in the Appendix). This indicated that grazing exclusion improved the palatability of vegetation communities, but was constrained by water availability. Empirical and simulation studies show that the diversity of grasses is susceptible to interactions of livestock grazing and aridity (Guo et al., 2018; Rota et al., 2016).

\section{Vegetation phenology response to grazing exclusion in three grassland types}

Vegetation phenological stages tended to be earlier in fenced plots of three Mongolian grasslands in terms of the whole community. Grazing exclusion treatment stimulates the growth of shallow-rooted plants (Zhu et al., 2016b). Plants in Mongolian grasslands are assumed to have short roots to utilize water resource in the upper soil layer, since local arid environment does not allow much water to infiltrate into deep soil layers. Grazing exclusion can also lead to soil desiccation induced by an increase of water required by non-grazed plant species (Bergmeier, 1998). Moreover, the phenological development of taller plant species is less constrained by water availability than that of lower ones (Dorji et al., 2013). We further found that phenological periods of species differed in their response to grazing exclusion (see Fig. Al in the Appendix). Specifically, certain number of species had no changes or even negatively altered for phenological stages in fenced plots. This provides species-specific evidence for restoring degraded grasslands. In future, it is necessary to investigate soil moisture and temperature under grazing exclusion and grazed treatments in Mongolian grasslands, to obtain a general and mechanistic explanation of grazing exclusion effects on vegetation phenology. We are aware that the measurement of vegetation phenology in several days is not enough to assess its response to grazing exclusion, since we cannot identify how many times of grasses were eaten by livestock. Moreover, the regrowth of grazed plants was not adequately considered.

\section{Conclusion}

Our study shows that grazing exclusion by fence significantly affects vegetation characteristics and community diversity. The effects are strongly modulated by grassland type. Grazing exclusion by fence is not an effective way to restore the vegetation cover and the diversity of plant communities in degraded Mongolian grasslands. However, grazing exclusion may play a positive role in promoting the growth of palatable species. Appropriate alternative management practices, such as rotational grazing, reseeding and fertilization, should be considered for the grassland restoration. In addition, factors influencing vegetation phenology need a further study in Mongolian rangelands.

Acknowledgements. This work was funded by China Postdoctoral Science Foundation (2018M641072) and the National Natural Science Foundation of China (91837312). We thank anonymous reviewers for very constructive suggestions on the original manuscript. 


\section{REFERENCES}

[1] Adler, P. B., Milchunas, D. G., Lauenroth, W. K., Sala, O. E., Burke, I. C. (2004): Functional traits of graminoids in semi-arid steppes: a test of grazing histories. - Journal of Applied Ecology 41: 653-663. DOI: 10.1111/j.0021-8901.2004.00934.x.

[2] Ahlborn, J., Wehrden, H. von, Lang, B., Römermann, C., Oyunbileg, M., Oyuntsetseg, B., Wesche, K. (2020): Climate-grazing interactions in Mongolian rangelands: effects of grazing change along a large-scale environmental gradient. - Journal of Arid Environments 173. DOI: 10.1016/j.jaridenv.2019.104043.

[3] Augustine, D. J., Derner, J. D., Milchunas, D., Blumenthal, D., Porensky, L. M. (2017): Grazing moderates increases in C3 grass abundance over seven decades across a soil texture gradient in shortgrass steppe. - Journal of Vegetation Science. DOI: $10.1111 /$ jvs.12508.

[4] Bergmeier, E. (1998): Flowering intensity of phrygana plants after fencing. - Israel Journal of Plant Sciences 46: 41-46. DOI: 10.1080/07929978.1998.10676706.

[5] Bosch, O. J. H. (1989): Degradation of the Semi-Arid Grasslands of Southern-Africa. Journal of Arid Environments 16: 165-175. DOI: 10.1016/S0140-1963(18)31023-1.

[6] Connell, J. H. (1979): Intermediate-disturbance hypothesis. - Science 204: 1345-1345. DOI: $10.1126 /$ science.204.4399.1345.

[7] Davies, K. W., Boyd, C. S. (2019): Grazing is not binomial (i.e., grazed or not grazed): A reply to Herman. - Bioscience 70: 6-7. DOI: 10.1093/biosci/biz138.

[8] Deng, L., Zhang, Z. N., Shangguan, Z. P. (2014): Long-term fencing effects on plant diversity and soil properties in China. - Soil \& Tillage Research 137: 7-15. DOI: 10.1016/j.still.2013.11.002.

[9] Díaz, S., Lavorel, S., McIntyre, S. U. E., Falczuk, V., Casanoves, F., Milchunas, D. G., Skarpe, C., Rusch, G., Sternberg, M., Noy-Meir, I., Landsberg, J., Zhang, W. E. I., Clark, H., Campbell, B. D. (2007): Plant trait responses to grazing - a global synthesis. - Global Change Biology 13: 313-341. DOI: 10.1111/j.1365-2486.2006.01288.x.

[10] Dorji, T., Totland, O., Moe, S. R., Hopping, K. A., Pan, J. B., Klein, J. A. (2013): Plant functional traits mediate reproductive phenology and success in response to experimental warming and snow addition in Tibet. - Global Change Biology 19: 459-472. DOI: 10.1111/gcb.12059.

[11] Goheen, J. R., Augustine, D. J., Veblen, K. E., Kimuyu, D. M., Palmer, T. M., Porensky, L. M., Pringle, R. M., Ratnam, J., Riginos, C., Sankaran, M., Ford, A. T., Hassan, A. A., Jakopak, R., Kartzinel, T. R., Kurukura, S., Louthan, A. M., Odadi, W. O., Otieno, T. O., Wambua, A. M., Young, H. S., Young, T. P. (2018): Conservation lessons from largemammal manipulations in East African savannas: the KLEE, UHURU, and GLADE experiments. - Annals of the New York Academy of Sciences 1429: 31-49. DOI: 10.1111 /nyas. 13848 .

[12] Golodets, C., Kigel, J., Sternberg, M. (2010): Recovery of plant species composition and ecosystem function after cessation of grazing in a Mediterranean grassland. - Plant and Soil 329: 365-378. DOI: 10.1007/s11104-009-0164-1.

[13] Guo, T., Lohmann, D., Ratzmann, G., Tietjen, B. (2016): Response of semi-arid savanna vegetation composition towards grazing along a precipitation gradient-The effect of including plant heterogeneity into an ecohydrological savanna model. - Ecological Modelling 325: 47-56. DOI: 10.1016/j.ecolmodel.2016.01.004.

[14] Guo, T., Weise, H., Fiedler, S., Lohmann, D., Tietjen, B. (2018): The role of landscape heterogeneity in regulating plant functional diversity under different precipitation and grazing regimes in semi-arid savannas. - Ecological Modelling 379: 1-9. DOI: 10.1016/j.ecolmodel.2018.04.009.

[15] Irisarri, J. G. N., Derner, J. D., Porensky, L. M., Augustine, D. J., Reeves, J. L., Mueller, K. E. (2016): Grazing intensity differentially regulates ANPP response to precipitation in 
North American semiarid grasslands. - Ecological Applications 26: 1370-1380. DOI: $10.1890 / 15-1332$.

[16] Jing, Z. B., Cheng, J. M., Su, J. H., Bai, Y., Jin, J. W. (2014): Changes in plant community composition and soil properties under 3-decade grazing exclusion in semiarid grassland. - Ecological Engineering 64: 171-178. DOI: 10.1016/j.ecoleng.2013.12.023.

[17] Kemp, D. R., Han, G. D., Hou, X. Y., Michalk, D. L., Hou, F. J., Wu, J. P., Zhang, Y. J. (2013): Innovative grassland management systems for environmental and livelihood benefits. - Proceedings of the National Academy of Sciences of the United States of America 110: 8369-8374. DOI: 10.1073/pnas.1208063110.

[18] Khishigbayar, J., Fernandez-Gimenez, M. E., Angerer, J. P., Reid, R. S., Chantsallkham, J., Baasandorj, Y., Zumberelmaa, D. (2015): Mongolian rangelands at a tipping point? Biomass and cover are stable but composition shifts and richness declines after 20 years of grazing and increasing temperatures. - Journal of Arid Environments 115: 100-112. DOI: 10.1016/j.jaridenv.2015.01.007.

[19] Koch, M., Schroder, B., Gunther, A., Albrecht, K., Pivarci, R., Jurasinski, G. (2017): Taxonomic and functional vegetation changes after shifting management from traditional herding to fenced grazing in temperate grassland communities. - Applied Vegetation Science 20: 259-270. DOI: 10.1111/avsc.12287.

[20] Li, Q., Zhou, D. W., Jin, Y. H., Wang, M. L., Song, Y. T., Li, G. D. (2014): Effects of fencing on vegetation and soil restoration in a degraded alkaline grassland in northeast China. - Journal of Arid Land 6: 478-487. DOI: 10.1007/s40333-013-0207-6.

[21] Li, S. G., Asanuma, J., Eugster, W., Kotani, A., Liu, J. J., Urano, T., Oikawa, T., Davaa, G., Oyunbaatar, D., Sugita, M. (2005): Net ecosystem carbon dioxide exchange over grazed steppe in central Mongolia. - Global Change Biology 11: 1941-1955. DOI: 10.1111/j.1365-2486.2005.01047.x.

[22] Marco, D. E., Silvertown, J. (2014): Size-dependent flowering in relation to grazing in a short-lived monocarpic perennial. - Advances in Ecology 2014: 7. DOI: $10.1155 / 2014 / 346352$.

[23] Moore, K. J., Moser, L. E., Vogel, K. P., Waller, S. S., Johnson, B. E., Pedersen, J. F. (1991): Describing and quantifying growth-stages of perennial forage grasses. Agronomy Journal 83: 1073-1077. DOI: 10.2134/agronj1991.00021962008300060027x.

[24] Mysterud, A. (2006): The concept of overgrazing and its role in management of large herbivores. - Wildlife Biology 12: 129-141. DOI: 10.2981/09096396(2006)12[129:TCOOAI]2.0.CO;2.

[25] R Core Team (2017): R: A Language and Environment for Statistical Computing. - R Foundation for Statistical Computing, Vienna, Austria. https://www.R-project.org/.

[26] Rota, C., Manzano, P., Carmona, C. P., Malo, J. E., Peco, B. (2016): Plant community assembly in Mediterranean grasslands: understanding the interplay between grazing and spatio-temporal water availability. - Journal of Vegetation Science 28: 149-159. DOI: $10.1111 /$ jvs. 12470 .

[27] Sagar, R., Li, G. Y., Singh, J. S., Wan, S. Q. (2019): Carbon fluxes and species diversity in grazed and fenced typical steppe grassland of Inner Mongolia, China. - Journal of Plant Ecology 12: 199-199. DOI: 10.1093/jpe/rtx069.

[28] Solen, L., Finger, R., Buchmann, N., Gosal, A. S., Hortnagl, L., Huguenin-Elie, O., Jeanneret, P., Luscher, A., Schneider, M. K., Huber, R. (2019): Assessment of spatial variability of multiple ecosystem services in grasslands of different intensities. - Journal of Environmental Management 251. DOI: 10.1016/j.jenvman.2019.109372.

[29] Stahlheber, K. A., D’Antonio, C. M. (2013): Using livestock to manage plant composition: a meta-analysis of grazing in California Mediterranean grasslands. Biological Conservation 157: 300-308. DOI: 10.1016/j.biocon.2012.09.008.

[30] Stein, C., Harpole, W. S., Suding, K. N. (2016): Transitions and invasion along a grazing gradient in experimental California grasslands. - Ecology 97: 2319-2330. DOI: 10.1002/ecy.1478. 
[31] Vermeire, L. T., Strong, D. J., Waterman, R. C. (2018): Grazing history effects on rangeland biomass, cover and diversity responses to fire and grazing utilization. Rangeland Ecology \& Management 71: 770-775. DOI: 10.1016/j.rama.2018.05.001.

[32] Wang, B., Wu, L. J., Chen, D. M., Wu, Y., Hu, S. J., Li, L. H., Bai, Y. F. (2019): Grazing simplifies soil micro-food webs and decouples their relationships with ecosystem functions in grasslands. - Global Change Biology. DOI: 10.1111/gcb.14841.

[33] Wang, D., Wu, G. L., Zhu, Y. J., Shi, Z. H. (2014): Grazing exclusion effects on aboveand below-ground $\mathrm{C}$ and $\mathrm{N}$ pools of typical grassland on the Loess Plateau (China). Catena 123: 113-120. DOI: 10.1016/j.catena.2014.07.018.

[34] Wang, J., Wei, H., Cheng, K., Ochir, A., Davaasuren, D., Li, P., Shun Chan, F. K., Nasanbat, E. (2020): Spatio-Temporal Pattern of Land Degradation from 1990 to 2015 in Mongolia. - Environmental Development: 100497. DOI: 10.1016/j.envdev.2020.100497.

[35] Weiss, L., Jeltsch, F. (2015): The response of simulated grassland communities to the cessation of grazing. - Ecological Modelling 303: 1-11. DOI: 10.1016/j.ecolmodel.2015.02.002.

[36] Wu, G. L., Du, G. Z., Liu, Z. H., Thirgood, S. (2009): Effect of fencing and grazing on a Kobresia-dominated meadow in the Qinghai-Tibetan Plateau. - Plant and Soil 319: 115126. DOI: 10.1007/s11104-008-9854-3.

[37] Xiong, D. P., Shi, P. L., Zhang, X. Z., Zou, C. B. (2016): Effects of grazing exclusion on carbon sequestration and plant diversity in grasslands of China. A meta-analysis. Ecological Engineering 94: 647-655. DOI: 10.1016/j.ecoleng.2016.06.124.

[38] Yao, X. X., Wu, J. P., Gong, X. Y., Lang, X., Wang, C. L., Song, S. Z., Ahmad, A. A. (2019): Effects of long-term fencing on biomass, coverage, density, biodiversity and nutritional values of vegetation community in an alpine meadow of the Qinghai-Tibet Plateau. - Ecological Engineering 130: 80-93. DOI: 10.1016/j.ecoleng.2019.01.016.

[39] Zhang, Y. Y., Zhao, W. Z. (2015): Vegetation and soil property response of short-time fencing in temperate desert of the Hexi Corridor, northwestern China. - Catena 133: 4351. DOI: 10.1016/j.catena.2015.04.019.

[40] Zhu, G. Y., Deng, L., Zhang, X. B., Shangguan, Z. P. (2016a): Effects of grazing exclusion on plant community and soil physicochemical properties in a desert steppe on the Loess Plateau, China. - Ecological Engineering 90: 372-381. DOI: 10.1016/j.ecoleng.2016.02.001.

[41] Zhu, J. T., Zhang, Y. J., Liu, Y. J. (2016b): Effects of short-term grazing exclusion on plant phenology and reproductive succession in a Tibetan alpine meadow. - Scientific Reports 6. DOI: 10.1038/srep27781.

[42] Zou, J. R., Luo, C. Y., Xu, X. L., Zhao, N., Zhao, L., Zhao, X. Q. (2016): Relationship of plant diversity with litter and soil available nitrogen in an alpine meadow under a 9year grazing exclusion. - Ecological Research 31: 841-851. DOI: 10.1007/s11284-0161394-3.

\section{APPENDIX}

\section{Determining the number of quadrats}

We found that mean vegetation cover of selected three quadrats was generally similar with that of ten quadrats regardless of treatments and grassland type. In addition, resampling based on the bootstrapping method little influenced mean vegetation cover of randomly combined three quadrats. Thus, three quadrats well depicted general changes in vegetation cover. We finally determined fixed three quadrats based on a rule of minimum differences between mean vegetation cover of three quadrats and that of total ten quadrats for each treatment and each grassland. 
Table A1. Mean vegetation cover (\%) of randomly sampled three quadrats from ten respectively in fenced and grazed plots for three grassland types in 2013

\begin{tabular}{c|c|c|c|c|c|c}
\hline & \multicolumn{2}{|c|}{ Meadow } & \multicolumn{2}{c|}{ Mountain steppe } & \multicolumn{2}{c}{ Dry steppe } \\
\hline Times & \multirow{2}{*}{ Treatment } & FG & GE & FG & GE & FG \\
\hline 1 & 24.56 & 22.79 & 92.43 & 93.23 & 61.03 & 56.12 \\
2 & 23.13 & 24.13 & 95.34 & 92.87 & 63.44 & 50.34 \\
3 & 22.87 & 22.31 & 91.17 & 94.39 & 61.38 & 51.32 \\
4 & 24.02 & 23.87 & 96.24 & 90.21 & 67.10 & 52.28 \\
5 & 23.46 & 24.04 & 94.46 & 91.32 & 65.88 & 51.46 \\
6 & 22.68 & 22.25 & 91.25 & 93.52 & 6.14 & 55.75 \\
7 & 22.30 & 23.12 & 93.45 & 92.80 & 62.34 & 54.32 \\
8 & 23.78 & 24.65 & 95.75 & 95.21 & 64.43 & 53.47 \\
9 & 24.37 & 23.84 & 92.19 & 93.47 & 65.26 & 55.89 \\
10 & 23.54 & 24.13 & 94.98 & 92.45 & 62.43 & 52.37 \\
\hline quadrats & 23.29 & 23.34 & 93.41 & 92.16 & 64.29 & 53.30 \\
\hline
\end{tabular}

\section{Response of vegetation community palatability to grazing exclusion}

Vegetation height of palatable species was higher than that of unpalatable species in the meadow and the mountain steppe. In contrast, this showed an opposite trend in the dry steppe. The richness of unpalatable species was much greater than that of palatable species. Vegetation cover indicated a similar trend. However, the cover dominance of unpalatable species did not exist in the meadow. In addition, grazing exclusion by fence generally increased the cover ratio and the richness of palatable species in the meadow and the mountain steppe. The effect was not available for the dry steppe. The richness of unpalatable species decreased in fenced plots compared to grazed ones in three grassland types.

Table A2. Vegetation height $(H)$ and richness $(R)$ of palatable species $(P)$ and non-palatable species (NP), as well as cover ratio (CR) of palatable species to the community under treatments of grazing exclusion by fence $(G E)$ and freely grazing $(F G)$ in three grassland types from 2013 to 2018

\begin{tabular}{|c|c|c|c|c|c|c|c|}
\hline Grasslands & Year & Treatment & $\mathbf{H}_{P}(\mathbf{c m})$ & $\mathbf{H}_{N P}(\mathbf{c m})$ & $\mathbf{R}_{P}$ & $\mathbf{R}_{N P}$ & $\mathbf{C R}_{P}$ \\
\hline \multirow{12}{*}{ Meadow } & \multirow{2}{*}{2013} & $\mathrm{GE}$ & 20.08 & 14.99 & 5.67 & 12.89 & 0.45 \\
\hline & & FG & 5.46 & 3.04 & 6.22 & 13.56 & 0.49 \\
\hline & \multirow{2}{*}{2014} & GE & 23.60 & 13.09 & 6.33 & 12.33 & 0.35 \\
\hline & & FG & 5.09 & 2.86 & 7.00 & 19.00 & 0.39 \\
\hline & \multirow{2}{*}{2015} & GE & 15.41 & 7.26 & 6.50 & 10.50 & 0.57 \\
\hline & & FG & 4.03 & 2.30 & 6.00 & 17.33 & 0.38 \\
\hline & \multirow{2}{*}{2016} & GE & 21.21 & 13.21 & 7.00 & 9.67 & 0.57 \\
\hline & & FG & 4.24 & 2.95 & 5.00 & 16.33 & 0.37 \\
\hline & \multirow{2}{*}{2017} & GE & 28.75 & 13.21 & 7.67 & 11.33 & 0.79 \\
\hline & & FG & 4.66 & 3.11 & 5.33 & 20.00 & 0.45 \\
\hline & \multirow{2}{*}{2018} & GE & 23.72 & 12.94 & 6.67 & 6.33 & 0.78 \\
\hline & & FG & 4.57 & 3.00 & 5.00 & 12.00 & 0.58 \\
\hline
\end{tabular}




\begin{tabular}{|c|c|c|c|c|c|c|c|}
\hline Grasslands & Year & Treatment & $\mathbf{H}_{P}(\mathbf{c m})$ & $\mathbf{H}_{N P}(\mathbf{c m})$ & $\mathbf{R}_{P}$ & $\mathbf{R}_{N P}$ & $\mathbf{C R}_{P}$ \\
\hline \multirow{12}{*}{ Mountain steppe } & \multirow{2}{*}{2013} & GE & 12.31 & 9.92 & 7.33 & 29.22 & 0.34 \\
\hline & & FG & 11.00 & 7.90 & 6.00 & 27.67 & 0.28 \\
\hline & \multirow{2}{*}{2014} & GE & 18.21 & 12.48 & 8.67 & 31.00 & 0.32 \\
\hline & & FG & 13.51 & 9.20 & 7.67 & 33.00 & 0.28 \\
\hline & \multirow{2}{*}{2015} & GE & 12.23 & 7.98 & 7.67 & 30.00 & 0.32 \\
\hline & & FG & 9.83 & 5.05 & 7.33 & 31.33 & 0.27 \\
\hline & \multirow{2}{*}{2016} & GE & 11.75 & 8.93 & 6.67 & 27.33 & 0.32 \\
\hline & & FG & 8.80 & 6.34 & 7.33 & 29.00 & 0.28 \\
\hline & \multirow{2}{*}{2017} & GE & 9.80 & 6.88 & 7.33 & 25.00 & 0.24 \\
\hline & & FG & 6.25 & 4.64 & 7.00 & 29.33 & 0.21 \\
\hline & \multirow{2}{*}{2018} & GE & 13.77 & 9.17 & 7.00 & 23.33 & 0.29 \\
\hline & & FG & 7.34 & 4.47 & 7.00 & 30.67 & 0.27 \\
\hline \multirow{12}{*}{ Dry steppe } & \multirow{2}{*}{2013} & GE & 7.27 & 13.29 & 1.20 & 11.10 & 0.01 \\
\hline & & FG & 4.18 & 11.26 & 1.33 & 11.67 & 0.02 \\
\hline & \multirow{2}{*}{2014} & GE & 7.73 & 11.51 & 1.63 & 12.40 & 0.01 \\
\hline & & FG & 3.00 & 9.86 & 1.86 & 16.86 & 0.01 \\
\hline & \multirow{2}{*}{2015} & GE & 3.29 & 7.79 & 2.10 & 12.20 & 0.02 \\
\hline & & FG & 2.57 & 5.43 & 2.00 & 16.86 & 0.04 \\
\hline & \multirow{2}{*}{2016} & GE & 6.63 & 7.77 & 1.50 & 10.70 & 0.02 \\
\hline & & FG & 5.39 & 5.75 & 2.00 & 15.43 & 0.04 \\
\hline & \multirow{2}{*}{2017} & GE & 6.67 & 6.87 & 1.78 & 11.10 & 0.03 \\
\hline & & FG & 3.31 & 4.26 & 2.71 & 15.29 & 0.06 \\
\hline & \multirow{2}{*}{2018} & GE & 10.20 & 10.01 & 2.30 & 12.20 & 0.04 \\
\hline & & FG & 5.68 & 7.08 & 2.86 & 16.71 & 0.12 \\
\hline
\end{tabular}

\section{Species distributions of phenological changes}

Species with negative phenological variations were generally the minority of grassland communities. Grazing exclusion advanced species phenological stages. However, the effects did not show a clear inter-annual regularity.

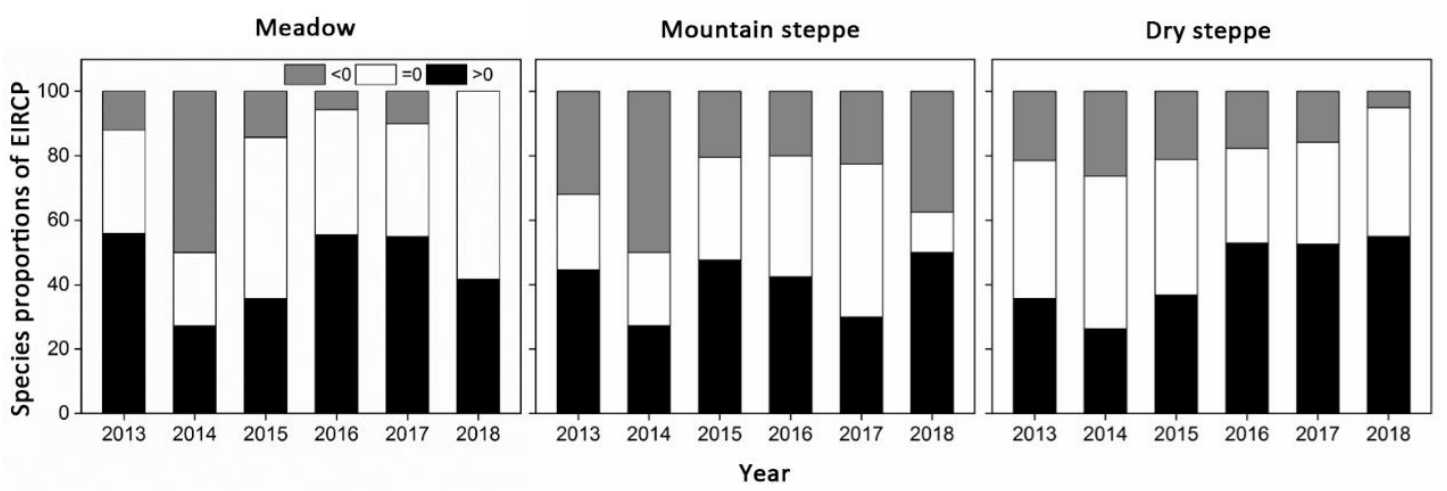

Figure A1. Species proportions of phenological changes (fenced plots vs. grazed plots) in three grassland types from 2013 to 2018 . The expression " $<0$ " denotes negative phenological variations; The expression " $=0$ " denotes no phenological variations; The expression " $>0$ " denotes positive phenological variations 